\title{
ANALYTICAL MODELLING FOR NEWTONIAN FLUID FLOW THROUGH AN ELASTIC TUBE
}

\author{
Abdessamad MEHDARI ${ }^{1}$, Mohamed AGOUZOUL ${ }^{2}$, Mohammed HASNAOUI ${ }^{3}$ \\ Mohamed V University, Rabat, Morocco, ${ }^{1}$ abdmehdari@gmail.com \\ Mohamed V University, Rabat, Morocco ${ }^{2}$,agouzoul@emi.ac.ma \\ Royal Air Force School, Marrakech, Morocco ${ }^{3}$,hasnaouimohammed@ @otmail.com
}

Abstract

The objective of the present work is to develop analytical modelling of an unsteady fluid flow through an elastic tube. The fluid is considered to be Newtonian and incompressible. The cylindrical tube wall boundaries are isotropic. The study provides a review of recent modelling aimed at understanding the effects of fluid parameters over the elastic tube wall behaviour. First of all, the fluid flow is analysed following an asymptotic approach according to a large Reynolds number and a small aspect radio. Second of all, the wall has been assumed to be a thin shell, which generates a small axisymmetric vibration. The mathematical model is developed according the thin shell theory. The dynamic behaviour of the tube wall is represented and discussed.

Keywords: analytical, modelling, newtonian, flow, elastic, tube,

\section{INTRODUCTION}

In the recent years, analytical modelling of flow through a deformable tube has attracted thorough attention. This is due to its occurrence for a diversity practice in many industrial systems and its capability to generate a variety of instabilities as using a rigid wall [1]. This standing is reflected in biology [2], in micro-fluidic devices [3,4], in the renewable energies [5], and Recently in the field of transporting gaseous materials under pressure [6] and in engineering $[7,8]$.

Although much numerical and experimental progress has been made during the past decades $[9,10]$, analytical modelling for Newtonian fluid flow through an elastic tube is not absolutely understood yet and remains to be discovered.

The present work focuses an analytical analysis of the fluid flow aspect and its effect on the tube wall behaviour. It is based on an asymptotic approach carried by a numerical simulation. In this model, the aspect ratio of the tube ' $\varepsilon$ ' presents a small parameter, which governs the flow asymptotic expansion. Moreover, based on linear approach of the thin shell theory, the equations of the motion of the tube wall are developed by asymptotic process founded on geodesic curvature parameter 2 .

The rest of this article is organized as follow. In Section 2, a formulation of the equations governing the problem is presented. The linearization approach is used to make an analytical solution is described in Section 3. An application with interpretation is given in Section 4. Finally, conclusion is drawn in Section 5.

\section{FORMULATION OF THE PROBLEM}

\subsection{Fluid}

In the presence of gravity force, we analyse an unsteady flow of an incompressible, viscous and Newtonian fluid in a symmetric axial cylindrical domain. $\rho$ and $v$ denote respectively the fluid density and the kinematic viscosity, $L$ is the tube length, $h$ is the thickness and Ro is the radius at rest. $R\left(z^{\prime}, t^{\prime}\right)$ is the variable radius (i.e. radius is a function of the longitudinal variable and time). We assume that the tube behaves as a homogenous, isotropic and linear elastic shell with $\rho_{t}$ is the tube density (Fig.1).

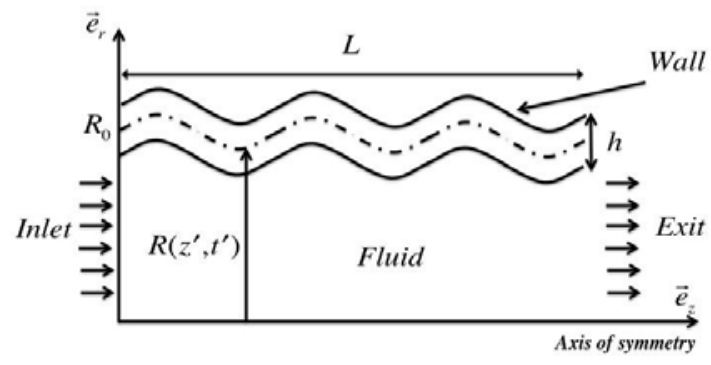

Fig. 1. Deformed domain

The physical variables are denoted using primes. At this level, we introduce dimensionless variables, namely: 


$$
\left\{\begin{array}{cl}
r=\frac{r^{\prime}}{R_{0}} \quad z=\frac{z^{\prime}}{L} \quad t=\frac{t^{\prime}}{T_{f}} \quad \varepsilon=\frac{R_{0}}{L} \\
u=\frac{u^{\prime}}{c W_{0}} \quad w=\frac{w^{\prime}}{W_{0}} \quad p=\frac{p^{\prime}}{\rho \varepsilon^{2} W_{0}^{2}} \\
r & : \text { radial displacement } \\
z & : \text { axial displacement } \\
t & : \text { time } \\
u & : \text { radial velocity } \\
w & : \text { axial velocity } \\
p & : \text { pressure }
\end{array}\right.
$$

Each dimensionless parameter of the above list accompanied by apostrophe $\left(^{\prime}\right)$ describes the corresponding physical parameter (with dimension).

Also, here $T_{f}$ is the fluid reference time, $\varepsilon$ ( $\varepsilon \prec \prec 1)$ is the aspect ratio and $W_{0}$ represents the inlet axial velocity.

Using system (1), the dimensionless NavierStokes and continuity equations of the problem, read as:

$$
\left\{\begin{array}{c}
\left(\frac{S_{t}}{\varepsilon}\right) \frac{\partial u}{\partial t}+u \frac{\partial u}{\partial r}+w \frac{\partial u}{\partial z}=-\frac{\partial p}{\partial r} \\
+\frac{\mathfrak{R}_{e}^{-1}}{\varepsilon}\left[\frac{1}{r} \frac{\partial}{\partial r}\left(r \frac{\partial u}{\partial r}\right)+\varepsilon^{2} \frac{\partial^{2} u}{\partial z^{2}}-\frac{u}{r^{2}}\right] \\
\left(\frac{S_{t}}{\varepsilon}\right) \frac{\partial w}{\partial t}+u \frac{\partial w}{\partial r}+w \frac{\partial w}{\partial z}=-\varepsilon^{2} \frac{\partial p}{\partial z} \\
+\frac{\mathfrak{R}_{e}^{-1}}{\varepsilon}\left[\frac{1}{r} \frac{\partial}{\partial r}\left(r \frac{\partial w}{\partial r}\right)+\varepsilon^{2} \frac{\partial^{2} w}{\partial z^{2}}\right] \\
\frac{\partial u}{\partial r}+\frac{u}{r}+\frac{\partial w}{\partial z}=0
\end{array}\right.
$$

The numbers figuring in (2) are the Reynolds number $\mathfrak{R}_{e}=\frac{R_{0} W_{0}}{v}$ and the Strouhalnumber $S_{t}=\frac{R_{0}}{W_{0} T_{f}}$.

At large Reynolds number and low Strouhal number, the system (2) is valid under the asymptotic restriction:

$$
\left\{\frac{S_{t}}{\varepsilon} \equiv O(1) \text { and } \quad \frac{\mathfrak{R}_{e}^{-1}}{\varepsilon} \equiv O(1)\right.
$$

The relation (03) reveals two important interactions physical characterizing our systems: the fluid flow unsteady and the fluid viscosity respectively with the geometry. These interactions present the coupling between the timescale and the nature of fluid with space scale. This approach, covering a several class of applications, is applied to studies of systemic arterial system. In particular, the blood flow modelling through vessels is assumed to be Newtonian.

\subsection{Tube}

The tube wall dynamic behaviour is analysed according to the thin shell theory [11-12]. More precise, the linear shell theory process adequately predicts the stresses and deformations relation for shells exhibiting a small elastic deformation [13]. For this purpose, the flexible tube is analytically modelled by using the non-linear Kirchhoff-Love theory [14]. The following system formulates the dimensionless variables and parameters:

$$
\left\{\begin{array}{c}
\varepsilon_{0}=\frac{h}{R_{0}} \quad \bar{R}=\frac{R}{R_{0}} \quad t=\frac{t^{\prime}}{T_{t}} \quad \varepsilon_{1}=\frac{h}{L} \\
\beta_{2}=\frac{\bar{u}_{0.2}}{L} \quad \gamma_{c}=\frac{\rho_{t} \cdot L^{2}}{\left(\lambda_{1}+\lambda_{2}\right) T_{t}^{2}} \quad \gamma_{f}^{0}=\frac{\rho W_{0}^{2}}{\lambda_{1}+\lambda_{2}} \quad(4) \\
\bar{P}_{3}^{*}=\frac{\left.P_{\text {ins }- \text { tube }}\right|_{r^{\prime}=R\left(z^{\prime}, t^{\prime}\right)-\frac{h}{2}}-P_{\text {out }- \text { tube }}}{\rho W_{0}^{2} \varepsilon^{2}} \\
P_{\text {ins -tube }}: \text { pressure inside the tube } \\
P_{\text {out }- \text { tube }}: \text { pressure outside the tube } \\
\bar{P}_{3}^{*} \quad: \text { dimensionless pressure gradient } \\
\bar{R}_{T_{t}=T_{f}}: \text { tube time reference } \\
\bar{u}_{0.2} \quad: \text { axial displacement reference } \\
1, \quad 2 \quad: \text { Lame constants. }
\end{array}\right.
$$

Where ${ }_{1},{ }_{0},{ }_{c}$ and ${ }_{f}^{0}$ are constants which characterize the problem.

In this section, we adopt the degenerate approach to better modelling the behaviour. This brings out asymptotic constraints stating in the following system:

$$
\left\{\varepsilon^{2} \equiv \varepsilon_{0} \quad \beta_{2} \equiv \frac{1}{\bar{R}} \frac{\partial \bar{R}}{\partial z} \quad \varepsilon_{1} \equiv \beta_{2}\right.
$$

Where $\frac{1}{\bar{R}} \frac{\partial \bar{R}}{\partial z}$ is the tube geodesic curvature along the $\vec{e}_{z}$.

According the system (5), the governing equations for the tube motion are reported in the under system:

$$
\left\{\begin{array}{l}
\beta_{2}\left(\frac{\lambda_{2}}{\lambda_{1}+\lambda_{2}}\right) \frac{\partial \bar{u}_{2}^{*}}{\partial z}-\beta_{2}^{2} \bar{u}_{2}^{*}+\gamma_{c} \beta_{2}^{1 / 3} \bar{R} \frac{\partial^{2} \bar{R}}{\partial t^{2}} \\
-\left(1-\frac{1}{\bar{R}}\right)-\gamma_{f}^{0} \bar{R} \bar{P}_{3}^{*}=0
\end{array}\right.
$$

$\bar{u}_{2}^{*}$ is the dimensionless wall axial displacement.

\subsection{Boundary condition}

In this section, we present the system dynamic boundary conditions. In fact, the condition for all 
velocity components base on non-slip hypothesis (the fluid particles adhere to the inner surface of the tube). Moreover, the both tube extremities are slotted and the system involves an axisymmetric behaviour. These conditions are written in the following form (Table 1):

Table 1. Boundary conditions

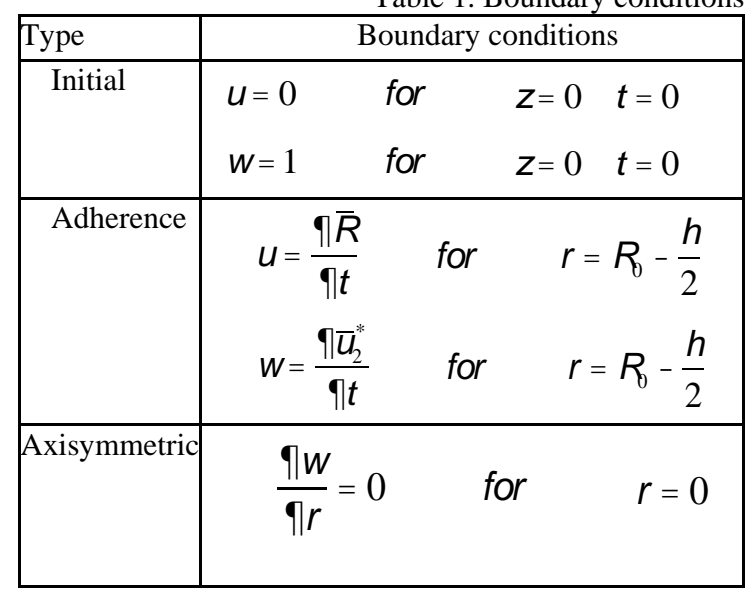

\section{LINEARIZED PROBLEM AND SOLUTIONS}

\subsection{Fluid}

Let us linearize system (2) about the particular solution at the inlet of the tube. Denoting by " $\varepsilon$ " the linearization parameter, the "Least Degeneration Principle" provides us the following form:

$\left\{\begin{array}{l}u=\varepsilon^{3} \bar{u} ; \quad w=1+\varepsilon^{3} \bar{w} ; \\ p=\bar{P}_{a m b}+\varepsilon^{3} \bar{p}\end{array}\right.$

Where $\bar{u}$ and $\bar{w}$ are respectively the perturbed radial and axial velocities and $\bar{p}$ is the perturbed pressure. $\bar{P}_{a m b}$ is the dimensionless ambient pressure:

$$
\left\{\begin{array}{l}
\bar{u}=0 \\
\bar{w}=0 \\
\bar{p}=0
\end{array} \quad \text { for } \quad r=z=t=0\right.
$$

Inserting (7) into (2), we obtain at order $\varepsilon^{3}$ included, the non-degenerate equations, namely:

The $0^{\text {th }}$ order terms:

$$
\left\{\begin{array}{c}
\frac{\partial \bar{u}}{\partial t}+\frac{\partial \bar{u}}{\partial z}=-\frac{\partial \bar{p}}{\partial r}+\left[\frac{1}{r} \frac{\partial}{\partial r}\left(r \frac{\partial \bar{u}}{\partial r}\right)-\frac{\bar{u}}{r^{2}}\right] \\
\frac{\partial \bar{w}}{\partial t}+\frac{\partial \bar{w}}{\partial z}=\left[\frac{1}{r} \frac{\partial}{\partial r}\left(r \frac{\partial \bar{w}}{\partial r}\right)\right] \\
\frac{\partial \bar{u}}{\partial r}+\frac{\bar{u}}{r}+\frac{\partial \bar{w}}{\partial z}=0
\end{array}\right.
$$

The $1^{\text {st }}$ order terms:

$$
\left\{\begin{array}{l}
\bar{u} \frac{\partial \bar{u}}{\partial r}+\bar{w} \frac{\partial \bar{u}}{\partial z}=0 \\
\bar{u} \frac{\partial \bar{w}}{\partial r}+\bar{w} \frac{\partial \bar{w}}{\partial z}=0
\end{array}\right.
$$

The $2^{\text {nd }}$ order terms:

$$
\left\{\begin{array}{c}
\frac{\partial^{2} \bar{u}}{\partial z^{2}}=0 \\
\frac{\partial^{2} \bar{w}}{\partial z^{2}}-\frac{\partial \bar{p}}{\partial z}=0
\end{array}\right.
$$

We remark that the equations (10) represent the non-linear convective terms. But, at this level, we look for the linearized solutions. So, the $1^{\text {st }}$ order terms are neglected and the analytical solution of the pressure is obtained:

$$
\left\{\begin{array}{c}
\bar{p}=\left[\begin{array}{c}
-\frac{A_{1}}{2} \sqrt{2} \sqrt{-I \omega} \cdot J_{0}\left(\frac{1}{2} \sqrt{2} \sqrt{-I \omega} \cdot r\right) \cdot z \\
+A_{2} \sqrt{-I \omega} J_{0}(\sqrt{-I \omega} \cdot r)
\end{array}\right] \cdot \mathrm{e}^{-I \omega t} \\
A_{1}=\frac{I \cdot \omega \cdot A_{2}\left[\begin{array}{l}
I \cdot \gamma_{f}^{0} \cdot \omega \cdot \sqrt{-I \omega} \cdot J_{0}(\sqrt{-I \omega}) \\
+J_{1}\left(\frac{1}{2} \sqrt{-I \omega}\right)
\end{array}\right]}{J_{1}\left(\frac{1}{2} \sqrt{2} \sqrt{-I \omega}\right)}
\end{array}\right.
$$

Where the $J_{0}$ and $J_{1}$ are the Bessel functions and $\omega$ is the fluid frequency. $A_{1}$ and $A_{2}$ are the complex numbers with $I$ is the imaginary unit.

\subsection{Tube}

To resolve the equation (6), we take up the linearization process around the initial equilibrium state. We introduce the linearized parameters $\beta_{2}$ $\left(\beta_{2} \prec \prec 1\right)$ :

$$
\left\{\begin{array}{c}
\bar{R}=1+\beta_{2}^{1 / 3} \tilde{R} \\
\bar{u}_{2}^{*}=\beta_{2}^{1 / 3} \tilde{u}_{2} \\
\bar{P}_{3}^{*}=\beta_{2}^{1 / 3} \tilde{P}_{3}
\end{array}\right.
$$

Where $\tilde{R}$ and $\tilde{u}_{2}$ are respectively the perturbed radial and axial wall displacement of the tube and $\tilde{P}_{3}$ is the perturbed pressure gradient.

Inserting (13) into (6), the approached solution is formulated at the $0^{\text {th }}$ order of $\beta_{2}^{1 / 3}$ by:

$$
\left\{\left.\gamma_{f}^{0} \tilde{P}_{3}\right|_{r \square 1}+\tilde{R}=0\right.
$$

The first relation analytically presents the linear correlate to fluid flow pressure to the wall deformation. This is in totally agreement with many numerical models [15-16].

\section{APPLICATION AND INTERPRETATIONS}

In order to investigate the dynamical behaviours of a three-dimensional flexible tube due to fluid- 
structure interaction, the present section aims to understand the blood flow mechanics in the main artery in the human body for blood pressures $80 \mathrm{mmHg}$ and $120 \mathrm{mmHg}$ : Aorta. On one hand, it is demonstrated that in medium and large arteries the blood can be assumed to be Newtonian. On the other hand, the Aorta natural elasticity affords to dampen the important pressure increases during the period of cardiac contraction (ventricular systole) and then the elastic return of this same wall during the period of cardiac rest (ventricular diastole) makes it possible to preserve in the arterial network a Minimum pressure (or diastolic pressure). The geometrical and numerical parameters of the simulation are listed in Table 2 (55 years old).

Table 2. Geometrical and numerical parameters

\begin{tabular}{|l|cc|}
\hline Parameter & \multicolumn{2}{|c|}{ Value/Unit } \\
\hline & \multicolumn{3}{|c|}{ Fluid } \\
\hline Density & 1060 & $\mathrm{Kg} / \mathrm{m}^{3}$ \\
Dynamic viscosity & 20 & $\mathrm{mPa} . \mathrm{s}$ \\
Reference Time & 1.4 & $\mathrm{sec}$ \\
Inlet axial velocity & 05 & $\mathrm{~cm} / \mathrm{s}$ \\
\hline \multicolumn{3}{|c|}{ Tube } \\
\hline Density & 1080 & $\mathrm{Kg} / \mathrm{m}^{3}$ \\
Young's modulus & 800 & $\mathrm{KPa}$ \\
Poisson's ratio & 0.45 & \\
Length & 22 & $\mathrm{~cm}$ \\
Radius & 10 & $\mathrm{~mm}$ \\
Thickness & 1.3 & $\mathrm{~mm}$ \\
\hline
\end{tabular}

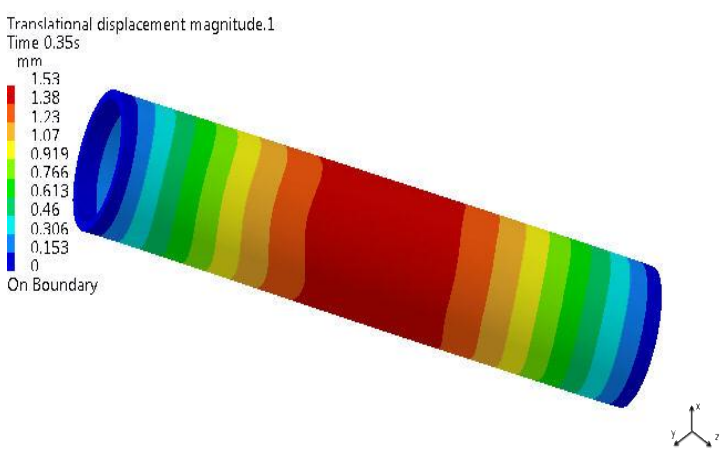

(a)

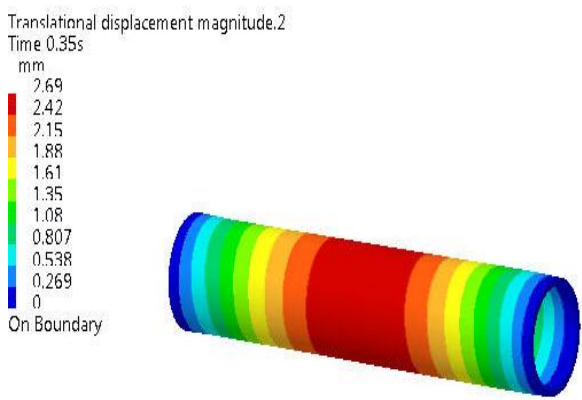

(b)

Fig. 2. Wall axial displacement at $\mathrm{t}=0.25$ $\left(t^{\prime}=0.35 \mathrm{sec}\right)$. (a) Blood pressure : $80 \mathrm{mmHg}$. (b) Blood pressure : $120 \mathrm{mmHg}$

The fig 2 illustrates the Aorta performance at $\mathrm{t}=0.25\left(\mathrm{t}^{\prime}=0.35 \mathrm{sec}\right)$ with system frequency in order to $21.28 \mathrm{~Hz}$. According the $\gamma_{f}^{0}$, the aorta's wall displacement exhibits normallybehaviour (0-2,5 $\mathrm{mm})$ [17]. Furthermore, the swelling degree of aorta is characterized respectively by strain $24.45 \%$ and strain $10.45 \%$ for $120 \mathrm{mmHg}$ and $80 \mathrm{mmHg}$. These results seem to be very consistent with the numerical and experimental literatures in terms of order of strain [18].According the said study, the strain, for the age range $50-59$, should be $18 \pm 9 \%$.

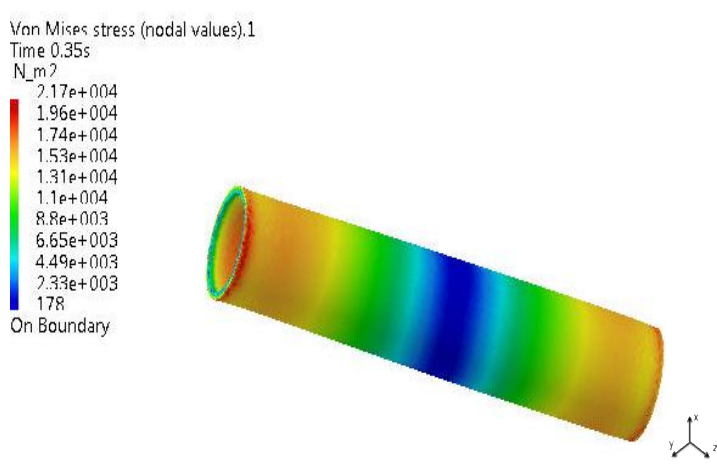

(a)

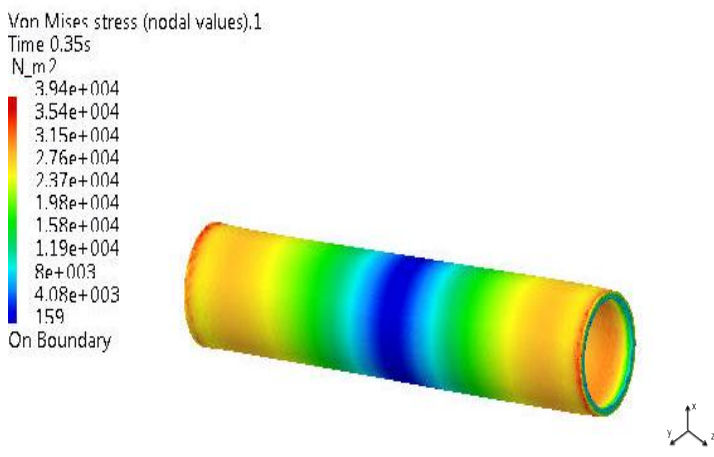

(b)
Fig. 3. Aortic wall stress at $\mathrm{t}=0.25\left(\mathrm{t}^{\prime}=0.35\right.$ sec). (a) Blood pressure : $80 \mathrm{mmHg}$. (b) Blood pressure : $120 \mathrm{mmHg}$

According the system frequency $(21.28 \mathrm{~Hz})$, the Fig 3 evaluates the potential of the Aorta stress at $\mathrm{t}^{\prime}=0.35$ sec. These findings reveal that, in descending Aorta, regions of low wall stress which are corresponding to regions high displacement (Fig 2 ), are predisposed to the development of plaque while the wall highly oscillating [19]. Moreover, The special evolution of the wall stress shows that this analytical approach result is positively compared with the many results $(0-100 \mathrm{KPa})$ [20] and the descending aorta distensibility (27.44\% $10^{-}$ $\left.{ }^{3} \mathrm{KPa}^{-1}\right)$ is in good agreement with the results taken from Redheuil [18] $\left(29 \pm 1310^{-3} \mathrm{KPa}^{-1}\right)$.

These results present conclusive evidence that the wall dilatation has an important correlate to age. This can be elucidated in light of the aortic distensibility with age. In fact, the increase in aortic size is more signified after the $5^{\text {th }}$ decade [18]. At this period the strain decreases that is the main developer for reduced distensibility. The Redheuil has determined the average distensibility as $60 \pm$ $1910^{-3} \mathrm{KPa}^{-1}$ for the individuals aged up to 50 and $21 \pm 910^{-3} \mathrm{KPa}^{-1}$ over 50[18]. The low distensibility 
of this study (55 years old) is in fair agreement with Redheuil and provides an accurate prediction of many cardiovascular events such as rupture risk of aortic aneurysms [21].

\section{CONCLUSION}

In this document, the fluid structure's interaction is analytically modelled. These findings enable us to evaluate of the aorta's wall behaviour containing human blood flow. This arterial stiffness assessment should afford a best prediction to many cardiovascular diseases, beyond traditional risk factors, which remain currently undetected with a normal blood pressure.

Subsequently, the aortic wall behaviour will be processed considering the axial velocity with a large interval frequency. This may help in better understandingthe limits of Aorta radial displacements and to manage several blood pressure range at large interval frequency.

\section{REFERENCES}

1. Mehdari A, Hasnaoui M, Agouzoul M. Modelling of flow through an elastic tube with a variable radius. 12eme Congrès de Mécanique2015. Casablanca. Maroc

2. Grotberg, JB, Oliver EJ. Biofluidmechanics in flexible tubes. Annual review of fluid mechanics, 2004, 36:121-147

3. Todd MS, Stephen R. Quake. Microfluidics: fluid physics at the nanoliter scale. Reviews of modern physics, 2005, 77: 977-1026.

4. Eggert MD, Kumar S. Observations of instability, hysterisis, and oscillation in low-Reynolds number flow past polymer gels. Journal of Colloid and Interface Science 2004, 274: 234-242

5. Babarit A, Gendron B, Singh J, Melis C, Jean P. Modélisation numérique et expérimentale d'un système houlomoteur électro-actif déformable. 13 Journées de l'hydrodyn 2012. Chatou, France.

6. Mitin A. Main gas pipelines: fracture resistance assessment of pipes. Journal of Mechanics Engineering and Automation 2013, 3: 127-140.

7. Anvar G,Trung B.L, Fotis S. A numerical approach for simulating fluid structure interaction of flexible thin shells undergoing arbitrarily large deformations in complex domains. Journal of computational physics 2015, 300:814-843.

https://doi.org/10.1016/j.jcp.2015.08.008

8. Blom DS, Van Zuijlen AH, Bijl H. Multi-level acceleration with manifold mapping of strongly coupled partitioned fluid-structure interaction. Journal ofComputer Methods in Applied Mechanics and Engineering 2015, 296: 211-231. https://doi.org/10.1016/j.cma.2015.08.004

9. Hansen TW, Staessen JA, Torp-Pedersen C, Rasmussen S, Thijs L, Ibsen J, Jeppesen J. Prognostic value of aortic pulse wave velocity as index of arterial stiffness in the general population. American Heart Association Circulation 2006,113:664-670. https://doi.org/10.1161/CIRCULATIONAHA.105.57 9342.

10. Kanyiri CW, Kinyanjui M, Giterere K. Analysis of flow parameters of a Newtonian fluid through a cylindrical collapsible tube. Journal of Spring Plus 2014, 3:566. DOI.10.1186/2193-1801-3-566.

11. Frey F, Studer MA. Analyse des structures et milieux continus: Coques, Presses polytechniques et universitaires romandes, 2003, Lausane. Suisse.

12. Kirchhoff GR. Uber das gleichgewicht und die bewegungeinerelastischenscheibe. Journal of Reine und angewandtemathematik 1850, 40:51-88.

13. Koiter WT. On the foundations of the linear theory of thin elastic shells. Proceedings of the Koninklijke Nederlandse Akademie van Wetenschappen1970, B73. 169-54.

14. Laroze S. Mecanique des structures Tome 1: Solides elastiques, plaques et coques, Chapitre III, Coques. Editions Cépaduès 2005. Toulouse, Fance.

15. Sochi T. The flow of Newtonian and power law fluids in elastic tubes, International Journal of NonLinear Mechanics 2014, 67:245-250.

16. Leibinger J, Dumbser M, Iben U, Wayand I. A pathconservative Osher-type scheme for axially symmetric compressible flows in flexible viscoelastic tubes. Journal Applied Numerical Mathematics 2016, 105:47-63. https://doi.org/10.1016/j.apnum.2016.02.001

17. Vassal JP, Avril S, Genovese K. Caractérisation des propriétés mécaniques d'un tronçon d'aorte par méthode inverse basée sur une mesure ex-vivo du champ de deformations. 19eme CongrèsFrançais de Mécanique 2009. Marseille- France.

18. Redheuil A, Yu WC, Colin OW,Mousseaux E, Cesar A, Yan R, Kachenoura N, Bluemke D, Lima JAC. Reduced Ascending Aortic Strain and Distensibility Earliest Manifestations Of vascular Aging in Humans. American Heart Association Hypertension2010,

https://doi.org/10.1161/HYPERTENSIONAHA.109. 141278.

19. Moore JE, Xu C, Glagov S, Zarins CK, Ku DN.Fluid wall shear stress measurements in a model of the human abdominal aorta: oscillatory behaviour and relationship to atherosclerosis. Journal of Atherosclerosis 1994, 110:225-240.

20. Crawford MH. Current diagnosis and treatment in cardiology. 4th edition, Lange current series. New York. USA. 2014.

21. Eric KS, Derek PN, Shanna RS, Ronald MF, Joseph EB, Robert CG, Joseph HG, Benjamin MJ. Impact of wall thickness and saccular geometry on the computational wall stress of descending thoracic aortic aneurysms. American Heart Assocaition. Meeting in Los Angeless. USA. 2012. http://doi/org/10.1161/CIRCULATIONAHA.112.000 $\underline{200}$.

Received 2017-09-29

Accepted 2017-12-15

Available online 2017-12-18

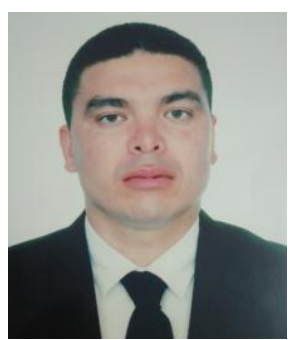

Abdessamad MEHDARI is an Aircraft Maintenance engineer. $\mathrm{He}$ graduated from the Royal Air Force School in 2006. He is a PhD student in Research and Development and Mechanical Multimedia Modeling Team which is a department of the Mohammadia Scholl of 
engineering at Mohammed V University of Rabat, Morocco. abdmehdari@gmail.com

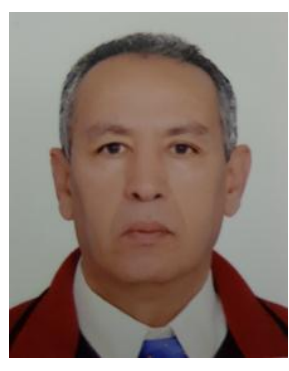

Mohamed AGOUZOUL, PhD, is full professor of mechanics at the Mohammadia Scholl of engineering of Rabat. He is the head of the department: Research and Development and Mechanical Multimedia Modeling Team at Mohammadia $\mathrm{V}$ University of Rabat, Morocco. agouzoul@emi.ac.ma

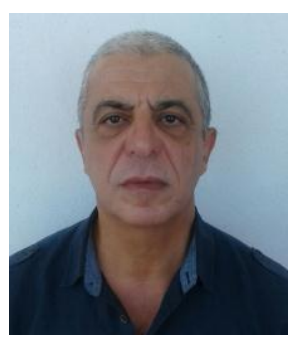

Mohammed HASNAOUI, $\mathrm{PhD}$, is full professor of mechanics at the Royal Air Force school of Marrakech. He is the head of the Structure and Material department.

hasnaouimohammed@hotmail.c om 